\title{
Editorial: Mobile Edge Computing and Personal Networks
}

\section{Bindhu ${ }^{1}$. Joy long-Zong Chen ${ }^{2} \cdot$ Subarna Shakya ${ }^{3} \cdot$ Z. Faizal Khan ${ }^{4}$}

Published online: 14 December 2019

(C) Springer Science+Business Media, LLC, part of Springer Nature 2019

\section{Editorial:}

The continuing growth of the mobile traffic and high demanding from the smart user developed the mobile edge computing architecture. It offers a high utilization of bandwidth and lesser latency to the application developers and content providers from the edge of the networks. Personal Networks provide a way to achieve success in the telecommunication path for effective and efficient networks. The convergence of mobile edge computing and personal networks provide the benefits to all entities which include supporters, vendors, tool integrators, technology providers, platform designer and application developer. Personal networks provide more authenticate and paying attention to the continuous monitoring status of the telecommunication path. Mobile edge computing gives full support to information storage and it helps to minimize the congestion during heavy traffic in personal networks. This plays a major role in $5 \mathrm{G}$ networks and provides the best services to end-users. This special issue has enlisted the state of art of the researches and addressed the solution for real time

V. Bindhu

vbindhuppg@gmail.com

Joy Iong-Zong Chen jchen@mail.dyu.edu.tw

Subarna Shakya

drss@ioe.edu.np

\section{Z. Faizal Khan}

faizalkhan@su.edu.sa

1 Electronics and Communication Engineering, PPG Instituzte of Technology, Coimbatore, India

2 Department of Electrical Engineering, Dayeh University, No. 168, Xuefu Road, Dacun Township, Changhua 515, Taiwan

3 Department of Electronics and Computer engineering, Pulchowk Campus, Institute of Engineering, Tribhuvan University, Kirtipur, Nepal

4 Department of Computer Science, College of Computing and Information Technology, Shaqra University, Shaqra 11564, Saudi Arabia applications in mobile edge computing and personal networks.

This special issue selects the six high-quality papers and it covers the implementation of mobile edge computing and applied in varies real time applications by using personal networks. The first article "Adaptive Proximate Computing Framework for Mobile Resource Augmentation" proposed proximate computing framework is intended to augment the resource scarcity of mobile devices by outsourcing their data and provides a feasible solution forth development of resource-intensive mobile application and its accessibility by the mobile user regardless of the resource scarcity of mobile device.

The second article titled "Fixing Target Access Point with low load during Handoff in WLAN" and its finding and fixing the best neighboring Access Point (AP) for Mobile Node which is in movement is a tedious task and provides the handoff considerably decreases the time to fix the target Access Point. The third article "Designing a Dynamic Topology (DHT) for Cluster Head Selection in Mobile Adhoc Network" exposed the number of parameters where analyzed in order to determine the selection of cluster head based on energy consumption and improved the operations of cluster computation in ad hoc environments effectively in relation to the cluster head selection and reduced energy consumption.

Next article titled "Fuzzy Rule Selection Using Hybrid Artificial Bee Colony with 2-Opt Algorithm for MANET" proposed fuzzy rule selection for the purpose of forwarding packets (being compared to that of conventional forwarding made to an approach with one node) and its efficiency by using the ABC-2 Opt algorithm on being compared with the selection of rule by using thick. The MANET nodes will not be stationary and the sender and the receiver may not always take similar paths of routing. This can be avoided by using the Fuzzy Rule Selection Using Hybrid Artificial Bee Colony with 2-Opt Algorithm.

The fifth article titled "Multi-Information Amount Movement Aware-Routing in FANET: Flying Ad-hoc Networks" deals the expansion of Mobility Aware DualPhase AODV with Adaptive Hello Messages (MA-DPAODV-AHM) convention and beats its partners as far as to 
start to finish delay, steering overhead, and bundle conveyance proportion execution measurements. This is added to the binary cross-layer directing along with the calculation that includes power controlling for responsively sending information via adorned to another Drone conditions.

The last article "Annealed Glowworm Optimization Graph Theory - Virtual Network Mapping for Home Healthcare in Cloud" enhances the utilization of network resources in cloud and maps a virtual network request (VNR) to an optimal physical node that satisfies the resource constraints. Experimental results show that the achievement of high mapping efficiency of the proposed work.

Acknowledgements The guest editors would like to thank to all our reviewers for their effective support and providing the review of manuscripts. We also extended our thanks to Edit-in-Chief, Dr. Imrich Chlamtac for his guidance and support during the entire process. Finally, we would like to thank the Springer publications for producing this volume.

Publisher's note Springer Nature remains neutral with regard to jurisdictional claims in published maps and institutional affiliations.

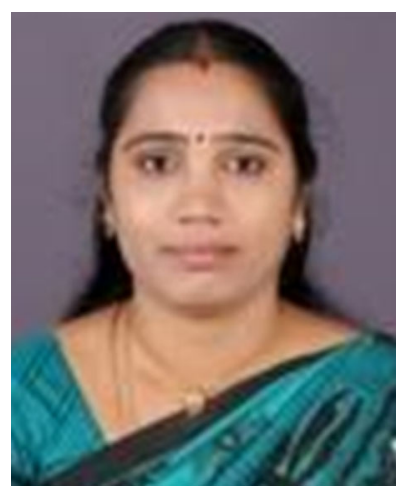

Dr. V. Bindhu received the B.E degree in Electronics and Communication Engineering from Bharathair University, Coimbatore in 2002 and M.E. Degree in Applied Electronics from Anna University, Chennai in 2007 and $\mathrm{PhD}$ Degree from Anna University, Chennai in 2014. Currently, she is a professor at PPG Institute of Technology, Coimbatore. Her area of interest includes Signal processing, and VLSI Design.

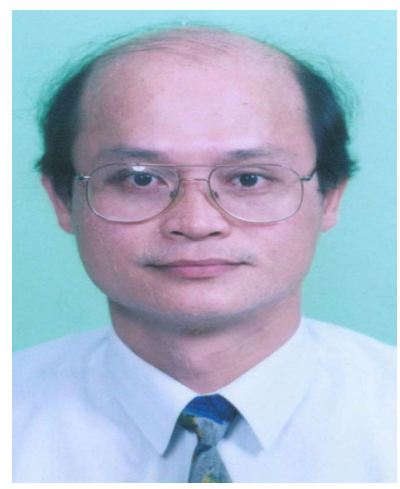

Dr. Joy long-Zong Chen is currently a full professor of Department of Electrical Engineering Dayeh University at Changhua Taiwan. Prior to joining the Dayeh University, he worked at the Control Data Company (Taiwan) as a technical manager since Sep. 1985 to Sep. 1996. His research interests include wireless communications, spread spectrum technical, OFDM systems, and wireless sensor networks. He has published a large number of SCI Journal papers in the issues addressed physical layer for wireless communication systems. Moreover, he also majors in developing some applications of the IOT (Internet of Thing) techniques and Dr. Joy I.-Z. Chen owned some patents authorized by the Taiwan Intellectual Property Office (TIPO).

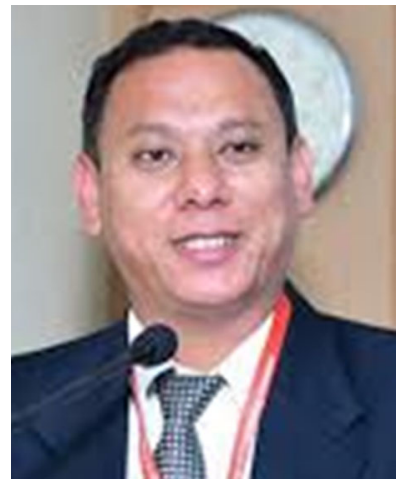

Dr. Prof. Subarna Shakya is currently a Professor of Computer Engineering, Department of Electronics and Computer Engineering, Central Campus, Institute of Engineering, Pulchowk, Tribhuvan University, Coordinator (IOE), LEADER Project (Links in Europe and Asia for engineering, education, Enterprise and Research exchanges ), ERA S M U S MUNDUS. She received MSc and $\mathrm{PhD}$ degrees in Computer Engineering from the Lviv Polytechnic National University, Ukraine, 1996 and 2000 respectively. Her research area includes E-Government system, Computer Systems \& Simulation, Distributed \& Cloud computing, Software Engineering \& Information System, Computer Architecture, Information Security for E-Government, Multimedia system.

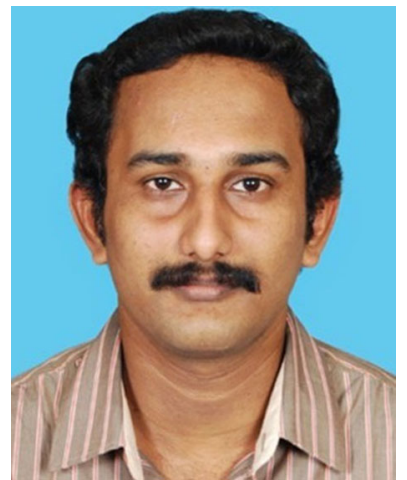

Dr. Z. Faizal Khan received B.E degree in Computer Science and Engineering from Anna University, Chennai in 2008 and M.E. degree in Computer Science and Engineering from Anna University Tirunelveli in 2010. $\mathrm{He}$ did his $\mathrm{PhD}$ research in the area of medical image processing at Anna University, Chennai. He has published more than 50 articles in referred journals and acted as an editorial member and reviewer in many reputed journals and conferences. His areas of interest include Medical image processing and Soft Computing. 